**PREPRINT: Manuscript accepted for publication in European Journal of Cancer Care.**

Coping in men with prostate cancer and their partners: a quantitative and qualitative study

Heather J. Green ${ }^{1}$, David J.N. Wells ${ }^{1,2}$, \& Liisa Laakso ${ }^{3}$

Heather J. Green BSc (Hons), PhD: Lecturer

${ }^{1}$ School of Psychology \& Griffith Institute for Health and Medical Research, Griffith

University, Gold Coast, Australia

David J. N. Wells BPsych (Hons): Doctoral Candidate

${ }^{2}$ Department of Psychology, James Cook University, Townsville, Australia

Liisa Laakso BPhysiotherapy (Hons), PhD, Grad Cert Health Management: Senior Lecturer

${ }^{3}$ School of Physiotherapy \& Exercise Science \& Griffith Institute for Health and Medical Research, Griffith University, Gold Coast, Australia

Acknowledgements: This research was conducted as part of a Bachelor of Psychology (Honours) program for David Wells at Griffith University, Gold Coast, Australia. We would like to acknowledge the contributions of Dr Scott McClintock and Mr Ian Platt for their assistance with participant recruitment and qualitative coding respectively. The assistance of the prostate cancer support group facilitators and study participants is gratefully acknowledged. We also thank two anonymous reviewers for their suggestions regarding the manuscript. There are no conflicts of interests for the authors of this work, financial or otherwise.

Correspondence should be addressed to: Dr Heather Green, School of Psychology, Gold Coast campus, Griffith University Qld 4222, Australia

Email: H.Green@griffith.edu.au; Phone +61 75552 9086; Fax: +61 755528291 


\begin{abstract}
$\underline{\text { Abstract }}$
This study investigated coping and quality of life in men with prostate cancer $(N=105,48-86$ years of age $)$ and their partners $(N=85,48-84$ years $)$. Participants completed the Abbreviated Dyadic Adjustment Scale, Brief COPE, European Organisation for Research and Treatment of Cancer Core Quality of Life Questionnaire (QLQ-C30) and open-ended questions on appraisal and coping. Multivariate analyses showed that better quality of life was associated with higher education levels (role functioning and fatigue), lower avoidant coping (emotional, social, and physical functioning and fatigue), and higher relationship satisfaction (emotional functioning). Use of medication or combined treatments was associated with worse physical and role functioning. Partners reported similar quality of life for patients as the patient ratings, except that partners reported patients' emotional functioning as significantly worse and social functioning as significantly better than the patients' own ratings. Patients and partners reported both positive and negative aspects to prostate cancer, and mentioned a range of coping strategies. Similarities between patients and partners in their responses to prostate cancer were identified using both quantitative and qualitative methods. Some differences within dyads were also noted and previous suggestions to incorporate partners and significant others in education and treatment were supported.
\end{abstract}

Keywords: Cancer, Carers, Quality of Life, Prostate Cancer, Psychological, Social 


\section{Coping in men with prostate cancer and their partners: a quantitative and qualitative study}

Prostate cancer is the most frequent malignancy in Australian males after skin cancer and is the second most common cause of male cancer deaths in Australia (Australian Institute of Health and Welfare and Australasian Association of Cancer Registries, 2007). Stressors associated with prostate cancer can include adjusting to the diagnosis, making treatment decisions, coping with treatment and side effects, and dealing with ongoing monitoring and health management. These stressors affect not only the person with cancer but also his family and significant supports (Australian Institute of Health and Welfare and Australasian Association of Cancer Registries, 2007, Baider and Bengel, 2001, Eton and Lepore, 2002, Franks and Roesch, 2006, Riechers, 2004). It is important to understand how individuals and families deal with the demands of chronic illness such as prostate cancer as this influences the degree and nature of adjustment and well-being of both the person with cancer and their partner or caregivers (Miller, 2000, Banthia et al., 2003). Literature on health-related quality of life and coping will be discussed before describing the present study.

\section{Coping and Quality of Life}

One way to measure adaptive outcome is health-related quality of life (HRQoL) (Bowling, 1991). HRQoL refers to an individual's subjective perceptions of wellbeing in multiple health domains, which may include elements such as physical, emotional, social, and spiritual functioning (Bowling, 1991, Ferrans et al., 2005). It is clear that a range of factors contribute to levels of HRQoL in men with prostate cancer (Wootten et al., 2007, Newton et al., 2007, Newton et al., 2006, Green et al., 2002) with characteristics of both the environment and the individual being major influences (Ferrans et al., 2005, Banthia et al., 2003, Eton and Lepore, 2002).

An influential theory in understanding adjustment to stressors such as cancer is Lazarus and Folkman's Stress and Coping model (Folkman and Greer, 2000, Lazarus and 
Folkman, 1984). In this model, responses to a potential stressor are mediated by the individual's cognitive appraisals and coping. A meta-analysis of coping strategies and adjustment for men with prostate cancer has found that men who used more approach coping (strategies directed towards a threat, such as planning or seeking information) and less avoidant coping (strategies deflected from a threat, such as substance use or self-distraction) were better off psychologically and physically than men with prostate cancer who used less approach and more avoidant coping (Roesch et al., 2005). To a smaller extent than for approach coping, both emotion- and problem-focused coping were also correlated with better adjustment (Roesch et al., 2005).

Other researchers have also concluded that there are detrimental effects of avoidant coping on adjustment (Costanzo et al., 2006, Perczek et al., 2002) but these studies have not found a conclusive relationship between approach coping and quality of life outcomes. This may in part be due to coping efforts being increased at times of distress (Green et al., 2002).

\section{Partner Reports of HRQoL and Coping}

In addition to patients' ratings of HRQoL, other studies have examined ratings of the patient's HRQoL by other informants, such as partners. Ratings by men with prostate cancer and their partners have tended to show close agreement on most dimensions of HRQoL (Wilson et al., 2000, Sneeuw et al., 2001). When there has been a difference, partners have tended to report worse HRQoL for the patient than the patient's own report. This has been found for mood, hot flushes, and perceived importance of the ability to have an erection (Wilson et al., 2000, who found close agreement on the remaining 14 of $17 \mathrm{HRQoL}$ dimensions) as well as physical function, role function, sleep difficulties, weight loss, and sexual satisfaction (Sneeuw et al., 2001, in the context of close agreement on the remaining 16 of 21 dimensions). 
Each person's perceptions of his or her own experiences may contribute differentially to coping and outcomes (Kershaw et al., 2008, Ptacek et al., 1999). Qualitative methods have found some differences between patient and partner perspectives. For example, interviews with 12 couples showed that patients with prostate cancer and their partners used similar coping strategies, but patients cited a greater range of coping strategies and higher frequency of use of such strategies than did their partners (Lavery and Clarke, 1999). Focus groups conducted separately with patients and partners, for 7 couples experiencing metastatic prostate cancer, found that patient accounts frequently included pre-diagnosis urinary and erectile symptoms, whereas partner accounts began with the diagnosis as the earliest event (Boehmer and Clark, 2001).

\section{Present Study}

Previous research has focused on coping either of individual patients or dyads, with research on the latter often excluding patients who do not have partners or those whose partners do not wish to participate. Similarly, many studies use either quantitative or qualitative methods, but not both. This research aimed to give voice to individual perspectives (Cameron et al., 2006) of patients with and without partners, as well as partners of these patients, by using both standardised measures and written responses to open-ended questions. It was hypothesised that, as found in previous research (Roesch et al., 2005), approach coping would be associated with better HRQoL and avoidant coping with worse HRQoL, when other potential predictors of HRQoL had been taken into account. It was also hypothesised that partners would rate patients' HRQoL either the same or lower than the patients would themselves. Written responses were expected to provide additional contextual and individual information. 
$\underline{\text { Methods }}$

\section{$\underline{\text { Participants }}$}

Participants were 105 men with prostate cancer aged 48-86 years $(M=67.8, S D=$ 6.8) and 85 partners of these patients aged $48-84$ years $(M=65.2, S D=6.6)$. Demographic and treatment information is summarised in Table 1. Ninety-nine patients (94.3\%) reported being in a relationship. The median time since diagnosis was 26 months (range 1-156 months). The "Highest Prostate Specific Antigen (PSA) level" had a median of $9.0 \mathrm{ng} / \mathrm{mL}$ (range 0-1760) while the "Most recent PSA level" had a median of $0.05 \mathrm{ng} / \mathrm{mL}$ (range 0170). The most frequent treatment reported was surgery (48\% of patients) followed by combined treatments $(25 \%)$. A wide range of education levels was represented. For example, $26 \%$ of patients and $54 \%$ of partners had completed Year 10 or less, and $14 \%$ of patients and $11 \%$ of partners had completed a university degree.

\section{Insert Table 1 about here}

\section{$\underline{\text { Materials }}$}

Patient and partner versions of questionnaires were used in order to measure demographics, treatment variables, coping, and HRQoL. Patients answered for themselves while partners answered HRQoL items in relation to the patient and the other items in relation to themselves. Patients self-reported their age, number of months since diagnosis, most recent PSA, highest PSA, treatment received in own words, education level, and relationship status. Partners recorded their age and education level.

Relationship Satisfaction. The Abbreviated Dyadic Adjustment Scale (ADAS) (Sharpley and Rogers, 1984) was used to measure relationship satisfaction and to determine whether there was any difference in relationship satisfaction between couples where the partner did or did not participate in the study. This 7-item scale has previously been reported to have a Cronbach's alpha of .76 and to differentiate between persons who are dissatisfied 
with their relationship and those who stay together (Sharpley and Rogers, 1984). In the present study Cronbach's alpha was .76 for patients and .73 for partners.

Coping. The Brief COPE (Carver, 1997) is a 28-item measure of coping strategies, with 2 items for each of 14 strategies. Responses range from 1 (I haven't been doing this at all) to 4 (I've been doing this a lot). A score for "Approach Coping" was computed as the mean response from items on active coping, planning, positive reframing, acceptance, using emotional support, and using instrumental support (Cronbach's alpha .88 for patients and .89 for partners). Similarly, "Avoidance Coping” was computed from items on humour, religion, self-distraction, denial, venting, substance abuse, behavioural disengagement, and self-blame (Cronbach's alpha .68 for patients and .77 for partners).

Health-Related Quality of Life. The European Organisation for Research and Treatment of Cancer Core Quality of Life Questionnaire (QLQ-C30, Aaronson et al., 1993) is a 30-item measure designed for cancer clinical research. Most items use a 4-point response ranging from 1 (Not at all) to 4 (Very much); two global items use a 7-point scale between 1 (Very poor) and 7 (Excellent). The multiple-item scales were used (Fayers et al., 2001) and had Cronbach's alpha of .62-.88 for patients' ratings. Partners' ratings for the patients gave Cronbach's alpha of .81-.94. The cognitive function scale was not analysed further due to low Cronbach's alpha (.55 and .52 for patients and partners respectively).

Open-Ended Questions. To access participants' personalised perceptions of appraisal and coping, three open-ended questions were included. The questions were: "Please describe any positive aspects of the diagnosis"; "Please describe any negative aspects of the diagnosis"; and "From the time of diagnosis until now please describe any strategies you used to cope with the diagnosis". Space was provided for free text responses.

\section{Procedure}


Participants were public or private patients of an urologist (36\% of respondents) or were contacted through prostate cancer support groups in Queensland, Australia (from six local support groups, all from the same umbrella organisation; 64\%). Respondents completed questionnaires in their own time and returned them via reply paid envelope. Pre-printed codes on patient and partner questionnaires allowed matching of responses from dyads. The study received ethics committee approval.

\section{Analyses}

In accordance with the manual for the quality of life measure, multiple item scales were computed if at least half the items were completed (Fayers et al., 2001). Nausea and pain showed floor effects, with almost all respondents replying Not at all to these questions. These two variables were not analysed further due to insufficient variability. In several cases patients omitted to answer certain measures (10 for highest PSA, 6 for most recent PSA, 2 for relationship satisfaction, and 1 for treatment). Three partners did not report their age or education, two did not report approach coping, and one did not report avoidant coping. As there was no systematic pattern to missing data, cases were included in analyses if they had valid scores on all variables in the specific analysis. As distributions of some measures showed skewness, non-parametric statistical tests were used to compare partner and patient reports. Wilcoxon's matched-pairs signed-ranks test and Spearman correlations were used to compare partner and patient reports for HRQoL (7 measures) and coping (2 measures) respectively.

Transformations were used to investigate linear relationships between potential predictors and HRQoL. For positively skewed variables, distributions were normal after square root (fatigue) or log transformations (avoidant coping). Time since diagnosis was dichotomised (up to 24 months and greater than 24 months). Negative skew was successfully corrected using reflect and square root transformations (partner relationship satisfaction, 
emotional functioning, social functioning, and global health status). Physical and role functioning were rated very highly by most participants and were therefore dichotomised to no difficulties at all (100) or some difficulties (less than 100). Hierarchical multiple regression was then used to examine blocks of predictors for each of the quality of life domains, to determine relative importance of predictors. Demographic and medical variables were entered first, followed by relationship satisfaction measures, and then coping measures. Logistic regression was used for the dichotomised quality of life variables, that is physical and role function.

Content analyses were conducted on responses to the three open-ended questions. For the questions on positive and negative aspects of the diagnosis, the second author read the responses and identified emergent themes. The open-ended question on coping strategies used since diagnosis was categorised into the same headings as the Brief COPE subscales. The responses to open-ended questions were then independently categorised using these themes by a psychology postgraduate student. Inspection of the numbers of positive and negative aspects identified by the raters revealed that ratings for more than $95 \%$ of cases were within one aspect in total. The coping strategies analysis revealed $75 \%$ agreement on the categorisation of coping strategies. 


\section{Results}

\section{$\underline{\text { Relationship Satisfaction }}$}

Relationship satisfaction was compared between partnered men whose partners did ( $n$ $=83 ; M=25.7, S D=4.3)$ or $\operatorname{did} \operatorname{not}(n=14 ; M=22.4, S D=2.9)$ participate in the study. Relationship satisfaction was significantly better among men whose partners participated, $t$ $(95)=2.72, p<.01$. There was no difference between patient and partner $(n=83 ; M=26.0$, $S D=4.4)$ ADAS ratings.

\section{$\underline{\text { Standardised Measures of HRQoL and Coping }}$}

Means and standard deviations for the standardised HRQoL and coping measures are in Table 2. Ratings for physical functioning were the highest among the HRQoL subscales, with the patient mean of 90.9 close to the scale maximum of 100, indicating few current physical limitations. The lowest HRQoL mean ratings were for social functioning and global health status/quality of life (means 72.4 and 72.7/100 respectively). Wilcoxon's matchedpairs signed-ranks test showed that patients reported significantly higher use of approach coping $($ median $=2.7, \mathrm{IQR}=2.0-3.1)$ than avoidant coping $($ median $=1.4, \mathrm{IQR}=1.2-1.7), Z$ $=-8.63, p<.001$. The approach mean represented a response between doing this a little bit and $a$ medium amount while the avoidant coping mean represented a response between $I$ haven't been doing this at all and doing this a little bit.

Insert Table 2 about here

\section{Comparison of Patient and Partner Ratings}

Ratings by partners and patients of the patient's HRQoL were compared by using Wilcoxon's matched-pairs signed-ranks test. Partners rated the patient's emotional functioning $($ median $=83.3, \mathrm{IQR}=66.7-100.0)$ as significantly worse than patients themselves (median $=83.3, \mathrm{IQR}=75.0-100.0), Z=-2.48, p<.05$. However, patients' social functioning was rated significantly better by the partners $($ median $=83.3, \mathrm{IQR}=66.7-100.0)$ 
than by patients $($ median $=66.7, \mathrm{IQR}=66.7-100.0), Z=-2.48, p<.05$. Spearman correlations between patient and partner ratings of the patient's HRQoL were all significant (see Table 2) and ranged from .45 (social functioning) to .73 (fatigue).

Patient and partner ratings for coping strategies were also examined. There was no significant difference in the mean ratings for avoidant strategies. There was a significant difference in use of approach coping strategies, $Z=-2.06, p<.05$. Patients reported greater use of approach coping $($ median $=2.7, \mathrm{IQR}=2.0-3.1)$ than did their partners $($ median $=2.3$, $\mathrm{IQR}=1.9-3.0)$.

\section{Predicting Health-Related Quality of Life}

Correlations between potential predictors and HRQoL are shown in Table 3. Older age was associated with a longer time since diagnosis, decreased likelihood of surgery as a sole treatment, and increased likelihood of medication or combined treatments. Completing a higher level of education was associated with significantly better role functioning and lower fatigue. Having surgery as the sole treatment was associated with better emotional function and lower fatigue. Medication or combined treatments were associated with higher avoidant coping and worse role and emotional functioning as well as increased fatigue. Higher relationship satisfaction was associated with more use of approach coping by the patient and higher approach and avoidant coping by the partner, as well as better emotional function but worse role function. Greater approach coping was positively associated with avoidant coping and also with higher fatigue. Higher avoidant coping was correlated significantly with worse emotional and social functioning as well as higher fatigue. Partner relationship satisfaction and approach coping showed similar correlations to the patients' equivalent variables, as can be seen from Table 3 (comparing variable pairs 6 and 7, and 8 and 10 respectively). For partner avoidant coping, however, the pattern of correlations differed somewhat from patient 
avoidant coping and there was a correlation between higher partner avoidance and worse patient role functioning, albeit at only a .05 level of significance.

Insert Table 3 about here

Hierarchical regressions used blocks of predictors, as shown in the categories in Table 3 (Step 1: 5 demographic and medical variables, Step 2: 2 relationship satisfaction variables; Step 3: 4 coping variables). As would be expected from the lack of significant bivariate correlations of the predictor variables with physical function and global health status, regressions for these dependent variables were not statistically significant at any of the three steps, for patients whose partners participated. Similarly, regression models were not significant for social function. For logistic regression predicting role function (no impairment compared with some impairment), the block of demographic and medical variables was statistically significant, $\chi^{2}(5)=21.90, p<.001$. Higher education, $B=.57, p<.01$ and having no history of medication or combined treatments, $B=-2.51, p<.05$, were both associated with better role function. Neither relationship satisfaction $\left(\chi^{2}\right.$ block $(2)=2.93$, ns $)$ nor coping variables $\left(\chi_{\text {block }}^{2}(4)=5.06, \mathrm{~ns}\right)$ added significantly to the prediction of role function. At the final step, the overall model remained statistically significant, $\chi^{2}(11)=29.88, p<.01$. Education remained a significant independent predictor, $B=.63, p<.01$ but medication/combined treatment was not a significant predictor at Steps 2 and 3.

For emotional function, demographic and medical variables were not significant predictors, $F(5,75)=1.68$, ns. With relationship satisfaction added, a significant $12 \%$ of variance in emotional function was accounted for, $F_{\text {change }}(2,73)=4.27, p<.05$. At Step 3, coping variables added further significant predictive value, $F_{\text {change }}(4,69)=4.37, p<.01$. With all predictors in the equation, $26 \%$ of variance in emotional function was accounted for, 
$F(11,69)=3.49, p<.001$, with significant independent contributions from higher patient relationship satisfaction ( $7 \%$ of variance) and lower avoidant coping (6\% of variance).

For fatigue, demographic and medical variables explained significant variance, $F(5$, $75)=3.11, p<.05$. Adjusted $\mathrm{R}^{2}$ showed that $12 \%$ of fatigue was accounted for at step 1 , with higher education showing a significant independent association with lower fatigue.

Relationship satisfaction did not add significantly to the prediction of fatigue, $F_{\text {change }}(2,73)<$ 1.0. Coping variables added significantly, $F_{\text {change }}(4,69)=4.13, p<.01$. At Step 3 , both higher education (6\% of variance) and lower use of avoidant coping (6\% of variance) were independently associated with reduced fatigue. With all predictors in the equation, $24 \%$ of variance in fatigue was accounted for, $F(11,69)=3.26, p<.001$.

Correlations and regressions were also rerun for the full sample $(N=105)$, by omitting variables that required partners (relationship satisfaction and partner coping variables). The weak correlation between medication or combined treatment and higher avoidant coping among patients with partners $(r[79]=.22, p<.05)$ was not significant in the full sample $(r[103]=.17$, ns). Several correlations were slightly increased and became statistically significant although non-significant in the sub-sample: better physical functioning was correlated with not having medication or combined treatment $(r[103]=-.26$, $p<.01)$ and with lower avoidant coping $(r[103]=-.26, p<.01)$. Similarly, better global health status was now associated with not having medication or combined treatment $(r$ [103] $=.22, p<.05)$ and lower avoidant coping $(r[103]=.23, p<.05)$ as well as a higher education level $(r[103]=-.21, p<.05)$.

Hierarchical regressions for emotional functioning and global health status $(N=105)$ were consistent with regressions from the subsample described above $(N=81)$. Emotional functioning was predicted by coping, with lower avoidant coping (13\% of variance) a significant independent predictor of better emotional function. Overall, $20 \%$ of variance in 
emotional functioning was accounted for, $F(7,97)=4.81, p<.001$. Regressions for global health status remained statistically non-significant, as in the subsample.

In role functioning, the only difference from the pattern of results in the subsample was that in the full logistic regression model, medication/combined treatment remained a significant independent predictor, $B=-2.65, p<.05$. Education was also significant in the full model, $B=.54, p<.01$, consistent with the regressions in the subsample. The overall model was statistically significant, $\chi^{2}(7)=27.56, p<.001$.

Prediction of fatigue showed a similar pattern of results as above, with the exception that use of medication or combined treatments was a significant independent predictor of increased fatigue at Step 1 (5\% of variance). In the final regression model, treatment was no longer a significant independent predictor and both higher education (6\% of variance) and lower use of avoidant coping ( $6 \%$ of variance) were independently associated with reduced fatigue. Twenty-eight percent of variance in fatigue was accounted for in the full model, $F$ (7, $97)=6.64, p<.001$.

In the full sample, in contrast to the subsample, physical function was predicted by demographic and medical variables, $\chi^{2}(5)=15.04, p<.01$. Use of medication or combined treatments was associated with worse physical functioning. Coping did not significantly add to prediction, $\chi^{2}(2)=4.47$, ns. However, with the addition of coping variables the overall model remained significant, $\chi^{2}(7)=19.51, p<.01$. Both medication or combined treatments, $B=-2.18, p<.05$, as well as higher avoidant coping, $B=-5.50, p<.05$, were associated with having impaired physical function.

For social functioning, neither demographic and medical variables nor coping variables had significant $\mathrm{F}$ change, but the overall regression model was significant with all predictors in the equation, $F(7,97)=2.34, p<.05$. Eight percent of variance was accounted for and lower avoidant coping (4\% of variance) made a significant independent contribution. 


\section{Qualitative Data}

Eighty-six patients and 64 partners responded to the open-ended questions. Up to 6 positive and 6 negative aspects were identified: among patients who responded there was a mean of $1.9(S D=1.2)$ and $1.8(S D=1.3)$ for the number of positive and negative aspects respectively. The themes that emerged were: Disease and Treatment, Interpersonal, Appreciation of Life, Health, and Life Priorities. It was found that the same themes could be applied to answers from either the "positive aspects" or "negative aspects" questions. Differences were negotiated between the raters until consensus was reached. Numbers of positive and negative aspects of the diagnosis were correlated $(r=.28, p<.05)$, indicating that patients who wrote more about negative aspects also tended to write more about positive aspects.

A question of interest was whether patients and their partners wrote similar responses to questions on negative and positive aspects of prostate cancer. Table 4 shows the percentage of respondents who mentioned specific categories of positive and negative aspects. The order of frequency of the categories was very similar for patients and partners, suggesting similar emphases for both types of respondent.

\section{Insert Table 4 about here}

The Disease and Treatment category was clearly the predominant theme cited. Within this category, male sexual dysfunction was mentioned as a negative aspect by $33 \%$ of partners and by $28 \%$ of patients. The next most frequent category was "Interpersonal". This category was mentioned as a positive aspect by both the partner (45\%) and patient (31\%). Positive interpersonal replies from partners were about the patient (44\%), family and friends (26\%), medical personnel (15\%), and others with prostate cancer (15\%). On the other hand the patients wrote most often about other men with prostate cancer $(41 \%)$, followed by medical personnel (24\%), family and friends (24\%) and then their partner (10\%). 
Eighty-four patients responded to the open-ended question on coping strategies. The majority of patients (64\%) reported using multiple coping strategies. The analysis showed instrumental support was mentioned by $37 \%$ of respondents, active coping by $32 \%$, positive reframing by $29 \%$, acceptance by $25 \%$, emotional support by $21 \%$, and planning by $15 \%$. Denial, venting, behavioural disengagement and self-blame were only mentioned by one patient each. When discussing information seeking following diagnosis, patients most often reported talking to other men with a previous diagnosis of prostate cancer or support groups (29.5\%). Reading (22\%) and using the internet (18.5\%) were also mentioned as information sources. Patients sought their emotional support firstly from family or partner (50\%), friends $(20 \%)$, medical staff $(10 \%)$, other men with prostate cancer $(10 \%)$ and support groups $(10 \%)$. The avoidant coping strategy of self-distraction was mentioned by $18 \%$, religion by $15 \%$, humour by $3.5 \%$ and the other avoidant strategies all had $1 \%$ usage. The avoidant strategy of self-distraction was reported as being comprised of physical activity (40\%; such as fishing, walking, gardening, or sport), work (33\%), meditation (20\%) and other (27\%).

Partner written coping strategies were also examined. The majority (52\%) of partners reported using multiple coping strategies. Forty-two percent of partners reported using instrumental support, 28\% emotional support, 22\% active coping and positive reframing, $18 \%$ acceptance and $15 \%$ religious coping. In terms of instrumental support, $38 \%$ referred to the patient, family or friends as their source of information, $25 \%$ used written materials, $21 \%$ used a cancer support group and $8 \%$ used the internet. For emotional support partners went to family and friends (65\%), their partner (15\%) and the support group (15\%).

\section{$\underline{\text { Discussion }}$}

In support of the multidimensional nature of quality of life, predictors were associated with different aspects of HRQoL. Multivariate analyses were conducted both with and without partner variables, showing that the only partner-related variable with a significant 
independent contribution was patient relationship satisfaction. Higher relationship satisfaction among partnered men whose partners participated was associated with better emotional function. Multivariate analyses also showed that higher education was associated with significantly better role functioning and reduced fatigue. Use of medication or combined treatments was associated with worse physical and role functioning. Additionally, lower use of avoidant coping was associated with better emotional, physical and social functioning and lower fatigue.

The findings lend support to past studies that have found detrimental effects of avoidant coping (Costanzo et al., 2006, Perczek et al., 2002) but have failed to find beneficial effects of approach coping (in contrast to Roesch et al., 2005). Treatment effects on quality of life have been found previously, with both beneficial and detrimental changes associated with treatments for prostate cancer (Green et al., 2002). The importance of relationship satisfaction to men's emotional well-being is consistent with previous findings for men with prostate cancer regarding partners' roles (Nanton et al., 2010) and perceived quality of social support (Queenan et al., 2010).

The second hypothesis was partially supported. Partners reported worse emotional functioning for patients than patients reported for themselves, consistent with previous research (Costanzo et al., 2006). However, partners rated patient social functioning more highly than patients and gave ratings in other domains that were consistent with patients' own ratings. Previous suggestions to include partners in both research and clinical treatment when possible were supported (Kershaw et al., 2008, Nanton et al., 2010, Street et al., 2010).

A contribution of this study was inclusion of both partnered and single patients, as well as partners who wished to participate. Mean relationship satisfaction was in the high range for both patients and partners (Sharpley and Rogers, 1984). Although still within the high satisfaction range, relationship satisfaction ratings from patients were significantly lower 
if their partners did not participate. This suggests that samples that rely on both partners participating are likely to be biased towards patients who are more satisfied in their relationships, as might be expected. However, supplementary t-tests showed that patients whose partners did not participate showed no significant differences on other coping and HRQoL variables from patients whose partners did participate. Similarly, single men did not show any differences from partnered men on coping and HRQoL or relationships among these variables.

In terms of specific coping strategies used by patients and disclosed in the open-ended questions the result is only partially consistent with past studies (Deimling et al., 2006, Green, 2003, Kershaw et al., 2008). However, in line with past studies (Franks and Roesch, 2006, Lavery and Clarke, 1999) was that the majority of patients and partners used multiple strategies when facing a prostate cancer diagnosis. Consistent with previous research, the present results support the hypotheses that avoidant coping may not be very helpful for improving quality of life in the longer-term and that there are some differences in how patients and their partners cope with the diagnosis. However, written responses help to clarify finer distinctions about coping. In free text, the major "avoidant" behaviour disclosed fits the Brief COPE category of self-distraction which mostly meant taking up physical activity and work. Physical activity is an important component of cancer treatment and would only be seen as a negative if it was used as an avoidant behaviour that genuinely displaced other methods of self-care to a detrimental extent.

The mention of sexual dysfunction by more partners than patients is consistent with some previous findings (Sneeuw et al., 2001) but not others (e.g. Couper et al., 2006) and may be because the majority of the sample came from prostate cancer support groups where this topic is freely talked about. That the disease and its treatment is predominant both as a positive and negative aspect supports discussion group research (Docherty et al., 2007) that 
acknowledgement of the disease is used as a coping strategy despite its potentially negative impact on the dyad. The identification of positive as well as negative aspects of the diagnosis by many patients and partners is consistent with previous research on the role of benefitfinding in adjustment to prostate cancer (Kinsinger et al., 2006).

The study's limitations are acknowledged. Participants would have included patients with different tumour stages and were not asked to report on characteristics such as stage, grade, or disease status. It can be inferred that the results are most likely to be generalisable to patients who have been living with the diagnosis for months or years and are relatively clinically well, because patients were recruited from outpatient care and prostate cancer support groups, $89 \%$ were at least 6 months post-diagnosis, and $65 \%$ reported their most recent PSA as less than or equal to $1 \mathrm{ng} / \mathrm{mL}$. Partners were not asked to identify their gender, so it is unclear what proportion of the sample, if any, came from same-sex couples. Selfreport data on treatment are limited by patients' understanding and recall of treatments. Although participants were asked to complete questionnaires separately, it is possible that some couples may have filled out surveys together. The social functioning scale in patients had relatively low reliability (Cronbach's alpha of .62 , compared with .85 for partners and $.76-.88$ for all other patient subscales that were analysed). The content analysis approach lacks some of the features of more robust qualitative methods.

Overall, results support previous research regarding giving consideration to both patient and partner coping and quality of life in both research and clinical practice. However, present results suggest that coping strategies and quality of life from dyads are also likely to apply for patients with prostate cancer who do not have partners or whose partners do not participate in research. 


\section{$\underline{\text { References }}$}

Aaronson N. K., Ahmedzai S., Bergman B., Bullinger M., Cull A., Duez N. J., Filiberti A., Flechtner H., Fleishman S. B., De Haes J. C. J. M., Kaasa S., Klee M., Osoba D., Razavi D., Rofe P. B., Schraub S., Sneeuw K., Sullivan M., Takeda F. \& The European Organization for Research and Treatment of Cancer Study Group on Quality of Life (1993) The European Organization for Research and Treatment of Cancer QLQ-C30: A quality-of-life instrument for use in international clinical trials in oncology. J Natl Cancer Inst 85, 365-376.

Australian Institute of Health and Welfare \& Australasian Association of Cancer Registries (2007) Cancer in Australia: an overview, 2006. Cancer series no. 37. Cat. no. CAN 32., Australian Institute of Health and Welfare, Canberra.

Baider L. \& Bengel J. (2001) Cancer and the spouse: gender-related differences in dealing with health care and illness. Crit Rev Oncol Hematol 40, 115-123.

Banthia R., Malcarne V. L., Varni J. W., Ko C. M., Sadler G. R. \& Greenbergs H. L. (2003) The effects of dyadic strength and coping styles on psychological distress in couples faced with prostate cancer. J Behav Med 26, 31-52.

Boehmer U. \& Clark J. A. (2001) Married couples' perspectives on prostate cancer diagnosis and treatment decision-making. Psycho-Oncol 10, 147-155.

Bowling A. (1991) Measuring health: A review of quality of life measurement scales, Open University Press, Buckingham.

Cameron E., Mathers J. \& Parry J. (2006) "Health and well-being": Questioning the use of health concepts in public health policy and practice. Crit Public Health 16, 347 - 354.

Carver C. S. (1997) You want to measure coping but your protocol's too long: Consider the Brief COPE. Int J Behav Med 4, 92-100.

Costanzo E. S., Lutgendorf S. K., Rothrock N. E. \& Anderson B. (2006) Coping and quality of life among women extensively treated for gynecologic cancer. Psycho-Oncol 15, 132-142.

Couper J., Bloch S., Love A., Macvean M., Duchesne G. M. \& Kissane D. (2006) Psychosocial adjustment of female partners of men with prostate cancer: a review of the literature. Psycho-Oncol 15, 937-953.

Deimling G. T., Wagner L. J., Bowman K. F., Sterns S., Kercher K. \& Kahana B. (2006) Coping among older-adult, long-term cancer survivors. Psycho-Oncol 15, 143-159.

Docherty A., Brothwell C. P. D. \& Symons M. (2007) The impact of inadequate knowledge on patient and spouse experience of prostate cancer. Cancer Nurs 30, 58-63.

Eton D. T. \& Lepore S. J. (2002) Prostate cancer and health-related quality of life: a review of the literature. Psycho-Oncol 11, 307-326.

Fayers P., Aaronson N., Bjordal K., Groenvold M., Curran D., Bottomley A. \& On Behalf of the Eortc Quality of Life Group (2001) The EORTC QLQ-C30 scoring manual, 3rd edn, European Organisation for Research and Treatment of Cancer, Brussels.

Ferrans C. E., Zerwic J. J., Wilbur J. E. \& Larson J. L. (2005) Conceptual model of healthrelated quality of life. J Nurs Scholarsh 37, 336.

Folkman S. \& Greer S. (2000) Promoting psychological well-being in the face of serious illness: When theory, research and practice inform each other. Psycho-Oncol 9, 11-19.

Franks H. M. \& Roesch S. C. (2006) Appraisals and coping in people living with cancer: a meta-analysis. Psycho-Oncol 15, 1027-1037.

Green H. J. (2003) The context of adjustment: qualitative reports from Australian men being treated for non-localised prostate cancer. Clin Psychol 7, 81-92. 
Green H. J., Pakenham K. I., Headley B. C. \& Gardiner R. A. (2002) Coping and healthrelated quality of life in men with prostate cancer randomly assigned to hormonal medication or close monitoring. Psycho-Oncol 11, 401-414.

Kershaw T. S., Mood D. W., Newth G., Ronis D. L., Sanda M. G., Vaishampayan U. \& Northouse L. L. (2008) Longitudinal analysis of a model to predict quality of life in prostate cancer patients and their spouses. Ann Behav Med 36, 117-128.

Kinsinger D. P., Penedo F. J., Antoni M. H., Dahn J. R., Lechner S. \& Schneiderman N. (2006) Psychosocial and sociodemographic correlates of benefit-finding in men treated for localized prostate cancer. Psycho-Oncol 15, 954-961.

Lavery J. F. \& Clarke V. A. (1999) Prostate cancer: Patients' and spouses' coping and marital adjustment. Psychol Health Med 4, 289-302.

Lazarus R. S. \& Folkman S. (1984) Stress, appraisal and coping, Springer Publishing, New York.

Miller J. F. (2000) Coping with chronic illness : overcoming powerlessness, 3rd edn, F.A. Davis, Philadelphia.

Nanton V., Osborne D. \& Dale J. (2010) Maintaining control over illness: a model of partner activity in prostate cancer. Eur J Cancer Care 19, 329-339.

Newton F., Burney S., Frydenberg M., Millar J. \& Ng K. (2007) Assessing mood and general health-related quality of life among men treated in Australia for localized prostate cancer. International Journal of Urology 14, 311-316.

Newton F. J., Burney S., Millar J. L., Frydenberg M. \& Ng K. T. (2006) Disease-specific quality of life among patients with localized prostate cancer: an Australian perspective. Br J Urol 97, 1179-1183.

Perczek R. E., Burke M. A., Carver C. S., Krongrad A. \& Terris M. K. (2002) Facing a prostate cancer diagnosis. Cancer 94, 2923-2929.

Ptacek J. T., Pierce G. R., Ptacek J. J. \& Nogel C. (1999) Stress and coping processes in men with prostate cancer: The divergent views of husbands and wives. J Soc Clin Psychol 18, 299-324.

Queenan J. A., Feldman-Stewart D., Brundage M. \& Groome P. A. (2010) Social support and quality of life of prostate cancer patients after radiotherapy treatment. Eur J Cancer Care 19, 251-259.

Riechers E. A. (2004) Including partners into the diagnosis of prostate cancer: A review of the literature to provide a model of care. Urol Nurs 24, 22-29, 38.

Roesch S. C., Adams L., Hines A., Palmores A., Vyas P., Tran C., Pekin S. \& Vaughn A. A. (2005) Coping with prostate cancer: a meta-analytic review. J Behav Med 28, 281293.

Sharpley C. F. \& Rogers H. J. (1984) Preliminary validation of the abbreviated Spanier Dyadic Adjustment Scale: Some psychometric data regarding a screening test of marital adjustment. Educ Psychol Meas 44, 1045-1049.

Sneeuw K. C. A., Albertsen P. C. \& Aaronson N. K. (2001) Comparison of patient and spouse assessments of health related quality of life in men with metastatic prostate cancer. J Urol 165, 478-482.

Street A. F., Couper J. W., Love A. W., Bloch S., Kissane D. W. \& Street B. C. (2010) Psychosocial adaptation in female partners of men with prostate cancer. Eur J Cancer Care 19, 234-242.

Wilson K. A., Dowling A. J., Abdolell M. \& Tannock I. F. (2000) Perception of quality of life by patients, partners and treating physicians. Qual Life Res 9, 1041-1052.

Wootten A. C., Burney S., Foroudi F., Frydenberg M., Coleman G. \& Ng K. T. (2007) Psychological adjustment of survivors of localised prostate cancer: investigating the 
role of dyadic adjustment, cognitive appraisal and coping style. Psycho-Oncol 16, 994-1002. 
Table 1

Demographic and Treatment Variables for Patients $(N=105)$ and Partners $(N=85)$

Patient Partner

\begin{tabular}{|c|c|c|c|c|}
\hline Age (means and standard deviations) & 67.8 & $(6.8)$ & 65.2 & $(6.6)$ \\
\hline Education Level (highest completed) & $n$ & $\%$ & $n$ & $\%$ \\
\hline Primary or Junior Secondary School & 27 & $(26 \%)$ & 44 & $(54 \%)$ \\
\hline Secondary School & 14 & $(13 \%)$ & 14 & $(17 \%)$ \\
\hline Trade Certificate or Diploma & 49 & $(47 \%)$ & 15 & $(18 \%)$ \\
\hline University Degree & 15 & $(14 \%)$ & 9 & $(11 \%)$ \\
\hline Time since diagnosis (median $\&$ range, in & 26 & $(1-156)$ & & \\
\hline \multicolumn{5}{|l|}{ months) } \\
\hline Most recent PSA (median \& range, in $\mathrm{ng} / \mathrm{mL}$ ) & 0.05 & $(0-170)$ & & \\
\hline Highest PSA (median \& range, in $\mathrm{ng} / \mathrm{mL}$ ) & 9.00 & $(0-1760)$ & & \\
\hline Treatment & $n$ & $\%$ & & \\
\hline Watchful Waiting & 7 & $(7 \%)$ & - & - \\
\hline Radiation & 2 & $(2 \%)$ & - & - \\
\hline Medical Intervention & 15 & $(14 \%)$ & - & - \\
\hline Surgery & 50 & $(48 \%)$ & - & - \\
\hline Combination treatments & 26 & $(25 \%)$ & - & - \\
\hline No treatment reported & 5 & $(5 \%)$ & - & - \\
\hline
\end{tabular}

Note Missing data on partner age ( $n=3)$, partner education (3), most recent PSA (6), and highest PSA (10). PSA = Prostate Specific Antigen 
Table 2

Means (with Standard Deviations) for Coping and Quality of Life Variables from Patients and Partners ${ }^{a}$

Variable
All Patients

$(n=105)$

Coping Strategy

Approach Coping

Avoidant Coping

$\underline{\text { HRQoL }}$

Global Health Status

$72.7 \quad(19.3)$

Physical Functioning

$90.9 \quad(14.0)$

$88.9(21.1)$

$81.3 \quad(19.2)$

$72.4 \quad(25.3)$

$24.6 \quad(22.8)$

Role Functioning

Emotional Functioning

Social Functioning

Fatigue
Patients with

participating

partner

$(n=85)$

$2.6 \quad(0.7)$

$(0.3)$

2.6

$(0.7)$

$1.5 \quad(0.3)$

1.5

$(n=85)$

Partners

.

$2.4^{\mathrm{b}}$

(0.7)

$(0.4)$

$(n=85)$

correlation
Dyadic

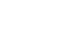

$.31 * *$

$31 * *$

${ }^{a}$ Patients rated themselves on all measures. Partners rated themselves on coping, but rated the patient on the quality of life variables.

${ }^{\mathrm{b}}$ Significantly different from patients, $p<.05$

**Correlation significantly different from zero, $p<.01$

$* * *$ Correlation significantly different from zero, $p<.001$ 


\section{Table 3}

Correlations Among Health-Related Quality of Life Measures and Potential Predictors in Patients Whose Partners Participated ( $n=81)$

\begin{tabular}{|c|c|c|c|c|c|c|c|c|c|c|c|c|c|c|c|c|}
\hline Variables & 1 & 2 & 3 & 4 & 5 & 6 & 7 & 8 & 9 & 10 & 11 & 12 & 13 & 14 & 15 & 16 \\
\hline \multicolumn{17}{|l|}{ Demographic } \\
\hline 1. Age & - & & & & & & & & & & & & & & & \\
\hline 2. Education level & .05 & & & & & & & & & & & & & & & \\
\hline \multicolumn{17}{|l|}{ Medical } \\
\hline 3. Time since diagnosis & $.32 * *$ & .17 & & & & & & & & & & & & & & \\
\hline 4. Surgery only & $-.39 * * *$ & .13 & -.21 & & & & & & & & & & & & & \\
\hline 5. Medication or combined & $.30 * *$ & -.21 & .20 & $-.77 * * *$ & & & & & & & & & & & & \\
\hline \multicolumn{17}{|c|}{$\underline{\text { Relationship Satisfaction }}$} \\
\hline 6. Self & .02 & -.11 & .00 & .05 & .12 & & & & & & & & & & & \\
\hline 7. Partner $^{\mathrm{R}}$ & -.06 & .22 & -.02 & -.02 & -.18 & $-.76 * * *$ & & & & & & & & & & \\
\hline \multicolumn{17}{|l|}{ Coping Strategies } \\
\hline 8. Approach (self) & .03 & .08 & -.01 & -.06 & .12 & $.31 * *$ & -.21 & & & & & & & & & \\
\hline 9. Avoidant (self) & -.22 & -.02 & -.08 & -.06 & $.22 *$ & .11 & -.13 & $.43 * * *$ & & & & & & & & \\
\hline 10. Approach (partner) & -.10 & -.05 & -.15 & -.12 & .22 & $.24 *$ & -.20 & $.31 * *$ & $.26^{*}$ & & & & & & & \\
\hline 11. Avoidant (partner) & -.10 & .01 & -.16 & .05 & .12 & $.29 * *$ & -.20 & $.23 *$ & $.33 * *$ & $.57 * * *$ & & & & & & \\
\hline \multicolumn{17}{|l|}{ HRQoL } \\
\hline 12. Physical Functioning & .01 & .12 & -.11 & .01 & $-.21^{\dagger}$ & .08 & .00 & -.03 & $-.17^{\dagger}$ & -.08 & -.10 & & & & & \\
\hline 13. Role Functioning & .01 & $.37 * * *$ & -.10 & .13 & $-.31 * *$ & $-.23 *$ & $.29 * *$ & -.14 & -.18 & -.17 & $-.26 *$ & $.57 * * *$ & & & & \\
\hline 14. Emotional Functioning ${ }^{\mathrm{R}}$ & .06 & -.08 & .10 & $-.25 *$ & $.31 * *$ & $-.26 *$ & .14 & .20 & $.38 * * *$ & .20 & .10 & $-.24 *$ & $-.30 * *$ & & & \\
\hline 15. Social Functioning ${ }^{R}$ & -.02 & -.07 & .13 & .01 & .18 & .09 & -.07 & .14 & $.27 *$ & -.05 & .15 & $-.38 * * *$ & $-.50 * * *$ & $.35^{* *}$ & & \\
\hline 16. Global Health Status ${ }^{\mathrm{R}}$ & -.07 & $-.15^{\dagger}$ & -.02 & -.16 & $.22^{\dagger}$ & -.19 & .07 & .03 & $.17^{\dagger}$ & .11 & .16 & $-.35 * *$ & $-.47 * * *$ & $.51 * * *$ & $.42 * * *$ & \\
\hline 17. Fatigue & .07 & $-.27 *$ & .11 & $-.24 *$ & $.35 * *$ & .16 & -.21 & $.23 *$ & $.40 * * *$ & $.24 *$ & $.29 * *$ & $-.58 * * *$ & $-.62 * * *$ & $.37 * * *$ & $.44 * * *$ & $.52 * * *$ \\
\hline
\end{tabular}

${ }^{\mathrm{R}}$ Reflect transformation used for correlations and regression, therefore a higher score now indicates lower functioning

${ }^{\dagger}$ Significant correlation in full sample only $(N=105)$. Apart from these relationships and a lack of correlation between variables 5 and 9 in the full sample, the pattern of correlations was the same in the full sample as in this table. 
Table 4

Positive and Negative Aspects, Percentage by Respondent.

\begin{tabular}{lrrrr}
\hline & \multicolumn{2}{c}{ Patient $(N=86)$} & \multicolumn{2}{c}{ Partner $(N=64)$} \\
& Positive & Negative & Positive & Negative \\
Disease/Treatment & 62 & 75 & 48 & 77 \\
Interpersonal & 31 & 13 & 45 & 25 \\
Appreciation of Life & 12 & 7 & 18 & 3 \\
Health & 12 & 2 & 11 & 0 \\
Life Priorities & 11 & 12 & 9 & 6 \\
\hline
\end{tabular}

